European Thyroid Journal
Eur Thyroid J 2017;6:12-19

DOI: $10.1159 / 000450977$
Received: June 27, 2016

Accepted after revision: September 21, 2016

Published online: November 8, 2016

\title{
Association between Serum Thyroid-Stimulating Hormone Levels and Visceral Adipose Tissue: A Population-Based Study in Northeast Germany
}

\author{
Tilman Witte ${ }^{a, b}$ Henry Völzke ${ }^{b}$ Markus M. Lerch ${ }^{c}$ Katrin Hegenscheid ${ }^{d}$ \\ Nele Friedrich ${ }^{\mathrm{e}}$ Till Ittermann ${ }^{\mathrm{b}}$ John A. Batsis ${ }^{\mathrm{a}} \mathrm{f}$ \\ ${ }^{a}$ The Dartmouth Institute for Health Policy and Clinical Practice, Geisel School of Medicine at Dartmouth, \\ Lebanon, N.H., USA; ${ }^{\mathrm{b}}$ Institute for Community Medicine, Departments of ${ }^{\mathrm{C}}$ Medicine A and ${ }^{\mathrm{d}}$ Diagnostic Radiology, \\ and ${ }^{\mathrm{e}}$ Institute of Clinical Chemistry and Laboratory Medicine, University of Greifswald School of Medicine, \\ Greifswald, Germany; ${ }^{\mathrm{f}}$ Department of Medicine, Geisel School of Medicine at Dartmouth, Hanover, N.H., USA
}

\section{Key Words}

Thyroid function - Thyroid-stimulating hormone .

Abdominal fat $\cdot$ Visceral body fat $\cdot$ Visceral adipose tissue . Leptin

\begin{abstract}
Background: Abdominal obesity is a major driver for adverse medical conditions. While an interaction between adipose tissue and thyroid function is thought to exist, to our knowledge, no study has examined the effect of thyroidstimulating hormone (TSH) on visceral adipose tissue (VAT) in a population-based context. Objective: We determined an association between serum TSH levels and VAT. Methods: A sample of 1,021 female and 956 male adults aged 20-79 years was drawn from registry offices in the cross-sectional, population-based Study of Health in Pomerania Trend (SHIP Trend) in Northeast Germany from 2008 to 2012. Our main exposure was serum TSH levels. Our main outcome was VAT measured using magnetic resonance imaging. The possibly mediating role of leptin on the TSH-VAT association was also assessed. Results: A total of 1,719 participants (87.9\%) had serum TSH levels within the reference range. The mean volume of VAT was 5.33 liters for men and 2.83 liters for women. No association between TSH and VAT $(\beta=0.06,95 \% \mathrm{Cl}:-0.02$,
\end{abstract}

0.14 ) was observed, and there were no differences detected between sexes. VAT was strongly associated with leptin with a greater effect in women than in men. Leptin was strongly associated with TSH. Conclusions: No association between TSH and VAT was observed. Other biomarkers such as leptin may play a role in the relationship between thyroid function and metabolic risk.

(c) 2016 European Thyroid Association Published by S. Karger AG, Basel

\section{Introduction}

Both thyroid disease and obesity are common disorders in the general population. Several studies have found a prevalence dependent on selected reference ranges from 0.1 to $2 \%$ for hypothyroidism [elevated thyroid-stimulating hormone (TSH), low thyroid hormones] and $>1 \%$ for hyperthyroidism (decreased TSH, elevated thyroid hormones) $[1,2]$. The prevalence for subclinical hypothyroidism (elevated TSH only) can range between 4 and $10 \%[1,2]$. Recent global reports estimate that $36.9 \%$ of men and $38.0 \%$ of women are classified as having obesity based on body mass index (BMI), and trends have shown

Till Ittermann and John A. Batsis contributed equally to this work. 
a considerable increase in the past few decades [3]. Similar increases in the proportion of obese people have been observed in Northeast Germany [4]. The Western Pomerania geographical region has experienced an increase from 24.7 to $32.0 \%$ in the proportions of individuals who were obese [4], making this region one of the highest prevalent regions in Germany (from 20.7\% in 2008 to $23.6 \%$ in 2011 on average) [5].

Several mechanisms have been proposed to describe the interaction between thyroid hormones and adipose tissue. Thyroid hormone induces energy utilization in white adipocytes through induction of uncoupling protein 1 expression [6]. In obesity, the expression of both the TSH receptor and thyroid hormone receptor gene was shown to be reduced in both subcutaneous (SAT) and visceral (VAT) adipose tissues [7]. Conversely, preadipocytes and other adipocytokines of those adipose tissues produce $\mathrm{fT}_{3}$ and may impact hypothalamic-pituitarythyroid axis activity [8].

Leptin is discussed as a potential mediator in the relationship between TSH and VAT [9]. It regulates the secretion of thyrotropin-releasing hormone and TSH directly on the level of the paraventricular nucleus and indirectly on the level of the arcuate nucleus $[10,11]$. Both the hypothalamic-thyroid axis and leptin loop system are known to modify certain signaling processes in the hypothalamic nuclei, but the association between them is still unclear $[12,13]$.

The assessment of the interplay between thyroid hormones and adipose tissue is further complicated by the inability to easily measure adiposity. Most studies use $\mathrm{BMI}$ as a surrogate measure for fat mass, and recent crosssectional studies demonstrated highly variable results with trends to significant associations between TSH and BMI [14-17]. Longitudinal studies have demonstrated predominantly a positive association between the change of serum TSH levels and the change of BMI or body weight [18-20]. However, others have demonstrated conflicting data proposing that lean body mass may impact thyroid function [21]. To account for differences in body mass and specifically body fat distribution, the actual VAT and SAT should ideally be measured with imaging technologies. In the 4 studies we found, inconsistent results were observed [22-25].

We (1) ascertained the association between serum TSH levels and VAT measured using whole magnetic resonance imaging (MRI), (2) determined whether thyroid function was associated with anthropometric measures, and (3) evaluated whether leptin influenced this relationship.

Association between TSH and Visceral Body Fat

\section{Subjects and Methods}

\section{Study Population}

The Study of Health in Pomerania Trend (SHIP-Trend) is an ongoing population-based cohort study carried out in West Pomerania, a region in Northeast Germany. The baseline survey was conducted from 2008 to 2012. A sample of adults aged 20-79 years was drawn from population registries out of the total population of 212,157 inhabitants, of which 8,016 inhabitants were invited to participate from 2008 to 2012 . The final cohort consisted of 4,220 subjects, all of whom gave their written informed consent (response 50.1\%). We excluded 2,449 participants because of missing MRI data and analyzed data from 1,971 participants. The institutional review boards at all respective institutions approved the conduct and secondary data analysis for this study.

\section{Assessments}

Trained and certified interviewers conducted a computer-aided personal interview to collect information on medical history, behavioral, and sociodemographic characteristics. Subjects were categorized into current, former, and never-smokers according to self-report. Self-reported average alcohol consumption relative to the last 30 days was calculated according to Baumeister et al. [26]. We defined physical activity as a self-report of sporting activities lasting at least $2 \mathrm{~h}$ a week. To calculate the equivalent income of a household, we divided the mean income by the square root of the number of people living in a household [27].

Blood samples were drawn between 7 a.m. and 1 p.m. from the antecubital vein and analyzed immediately in the hospital laboratory. Participants without known diabetes fasted at least $8 \mathrm{~h}$ before the examination. The median fasting time before blood sampling was $10.7 \mathrm{~h}$. We determined serum TSH levels through immunochemiluminescent procedures (Dimension Vista; Siemens Healthcare Diagnostics, Eschborn, Germany). The analytical sensitivity of the TSH assay was $0.005 \mathrm{mIU} / \mathrm{l}$, and the TSH working range was 0.005-100 mIU/l. The interassay coefficients of variations (CV) were $2.04 \%$ (low) or $2.20 \%$ (high) for TSH. We defined the TSH reference range as $0.49-3.29 \mathrm{mIU} / 1$ [28]. Levels of LDL cholesterol [CV: $3.9 \%$ (low) and 4.3\% (high)] and HDL cholesterol [CV: $4.7 \%$ (low) and 5.1\% (high)] were determined using the liquid selective detergent method (Dimension Vista), and cholesterol and triglyceride levels were assessed using photometric methods (Dimension Vista; Flex reagent cartridge; Dade Behring Ltd., Milton Keynes, UK). The CVs were 3.18 and $3.74 \%$ (cholesterol) and 3.4 and $4 \%$ (triglycerides).

A standardized protocol for the MRI examination was employed [29]. Participants without medication allergies had the option to undergo a contrast-enhanced examination. All examinations were performed on a 1.5-tesla machine (Magnetom Avanto; Siemens Medical Systems, Erlangen, Germany). Participants were placed in the supine position, and 5 phased array surface coils were placed on the head, neck, abdomen, pelvis, and lower extremities. The spinal coil was embedded in the patient table. The basic program included native whole-body MRI and secretin-enhanced MR cholangiopancreatography. Two trained technicians performed all examinations in a standardized manner. Data analysis was performed with 'ATLAS' (Automatic Tissue Labelling Analysis Software), which was specifically programmed for this purpose [30]. Two readers were trained for 2 weeks and independently deter-

Eur Thyroid J 2017;6:12-19 
mined visceral and subcutaneous body fat (intraclass correlation coefficient $>0.997$ ).

Body height was measured to the nearest $0.1 \mathrm{~cm}$ using a portable stadiometer (Soehnle Personenmessgerät; Soehnle Industrial Solutions, Backnang, Germany) and weight was measured to the nearest $0.1 \mathrm{~kg}$ with electronic scales (Soehnle S20, Soehnle Industrial Solutions, Backnang, Germany). BMI was calculated by taking the ratio of weight (in $\mathrm{kg}$ ) to height $(\mathrm{m})$ squared. Waist circumference was measured at the narrowest point between the last rib and the highest point of iliac crest to the nearest $0.1 \mathrm{~cm}$. Hip circumference was measured at the midpoint of the iliac crest and the most lateral projecting points of the greater trochanter to the nearest 0.1 $\mathrm{cm}$. The waist-to-hip ratio was calculated by taking the ratio of waist circumference to hip circumference, and the waist-to-height ratio was calculated as the ratio of waist circumference to height $(\mathrm{cm})$.

\section{Statistical Methods}

Quantitative characteristics are expressed as means \pm SD, and qualitative characteristics are expressed as total numbers and percentages. We tested for an effect modification by including interaction terms of TSH with sex and smoking status in the regression models [14]. We assessed TSH as a continuous variable, and subcategorized TSH as high, low, and normal, based on the reference range. The primary exposure of our analysis was serum TSH. The primary outcome was VAT. To account for nonparticipation in the voluntary MRI examination, we used inverse probability weights derived from logistic regression with participation in the MRI examination (yes/no) as outcome and adjusted for age, sex, level of education, income, marital status, smoking status, physical activity, BMI, diabetes, cholesterol, triglycerides, TSH, systolic, and diastolic blood pressure, hypertension medication, and hemoglobin $A_{1 C}$ as exposures. For all subsequent regression analyses, we used fractional polynomials to test for potential nonlinear associations. Unadjusted regression models ( $\beta$-coefficient, $95 \% \mathrm{CI}$ ) were assessed. $\beta$-Coefficients were utilized to ensure the variances of dependent and independent variables were a value of 1 [i.e. an increase of $1 \mathrm{mU} / \mathrm{l}$ TSH equals an increase of $\mathrm{x}$ ( $\beta$-coefficient) liter fat)], when the main exposure and outcome variable were considered. Our multivariable model was adjusted for age, sex, smoking status, physical activity, and alcohol intake. We performed an exploratory analysis by performing a regression model of VAT and leptin, and leptin and TSH, adjusting for the same confounders as above. As serum leptin levels were available in a subsample of 851 participants, we created an inverse probability weight in a similar fashion, and multiplied for the leptin analyses the weight with the previous MRI weight. To minimize the effect of outliers on the results, we power-transformed the leptin variable using the Royston-Sauer power transformation method [31]. Lastly, we determined adjusted $\beta$-coefficients for differing anthropometric measurements and thyroid function. The outcomes of interest included BMI, waist and hip circumference, waist-hip ratio, and SAT. Separate models were constructed to assess each of these outcomes. $\mathrm{p}<0.05$ was initially considered statistically significant. We used the Bonferroni correction method to adjust for multiple comparisons [32]. The 21 comparisons in the main analysis yielded a new threshold of $\mathrm{p}<0.002$. Analyses were performed using Stata 14.0 (StataCorp, College Station, Tex., USA).
Table 1. Characteristics of the study population

\begin{tabular}{|c|c|c|c|}
\hline & Male & Female & $\mathrm{p}$ value \\
\hline Subjects, $\mathrm{n}$ & 956 & 1,021 & \\
\hline Age, years & $50.8 \pm 14.5$ & $50.9 \pm 13.4$ & 0.78 \\
\hline \multicolumn{4}{|l|}{ Sociodemographic factors } \\
\hline Smoking status & & & $<0.001$ \\
\hline Current smoker & $239(25.1)$ & $231(22.6)$ & \\
\hline Former smoker & $411(43.1)$ & $314(30.8)$ & \\
\hline Nonsmoker & $303(31.8)$ & $475(46.6)$ & \\
\hline Exercise, $>2 \mathrm{~h} /$ week & $672(70.5)$ & $734(71.3)$ & $<0.001$ \\
\hline Alcohol, g/day in last 7 days & $12.7 \pm 15.2$ & $4.1 \pm 5.9$ & $<0.001$ \\
\hline Equivalent income, EUR & $1,548 \pm 792$ & $1,382 \pm 673$ & $<0.001$ \\
\hline Married & $789(82.8)$ & $803(78.7)$ & $<0.001$ \\
\hline \multicolumn{4}{|l|}{ Comorbidities } \\
\hline Myocardial infarction & $12(1.3)$ & $3(0.3)$ & $<0.001$ \\
\hline Any diabetes & $82(8.6)$ & $81(7.9)$ & 0.59 \\
\hline \multicolumn{4}{|l|}{ Lipid profile } \\
\hline Total cholesterol, mmol/l & $5.41 \pm 1.08$ & $5.61 \pm 1.06$ & $<0.001$ \\
\hline LDL cholesterol, mmol/l & $3.43 \pm 0.92$ & $3.40 \pm 0.92$ & 0.52 \\
\hline HDL cholesterol, mmol/l & $1.30 \pm 0.32$ & $1.61 \pm 0.36$ & $<0.001$ \\
\hline Triglycerides, mmol/l & $1.75 \pm 1.25$ & $1.36 \pm 0.74$ & $<0.001$ \\
\hline Leptin, ng/ml & $6.91 \pm 4.85$ & $21.36 \pm 14.27$ & $<0.001$ \\
\hline \multicolumn{4}{|l|}{ Thyroid function } \\
\hline TSH, mIU/l & $1.26 \pm 0.75$ & $1.42 \pm 1.08$ & $<0.001$ \\
\hline \multicolumn{4}{|l|}{ Body composition measures } \\
\hline Visceral fat, liters & $5.33 \pm 2.82$ & $2.83 \pm 1.88$ & $<0.001$ \\
\hline Subcutaneous fat, liters & $6.88 \pm 2.89$ & $8.96 \pm 3.76$ & $<0.001$ \\
\hline BMI & $28.0 \pm 3.6$ & $27.1 \pm 4.9$ & $<0.001$ \\
\hline Waist circumference, $\mathrm{cm}$ & $95.3 \pm 10.8$ & $83.7 \pm 11.9$ & 0.38 \\
\hline Hip circumference, $\mathrm{cm}$ & $101 \pm 7.0$ & $102 \pm 10.5$ & $<0.001$ \\
\hline Waist-to-hip ratio & $0.94 \pm 0.07$ & $0.82 \pm 0.06$ & $<0.001$ \\
\hline Waist-to-height ratio & $0.54 \pm 0.02$ & $0.51 \pm 0.02$ & $<0.001$ \\
\hline
\end{tabular}

Data are expressed as means \pm SD for continuous data or as n (\%) for categorical data.

\section{Results}

A total of $87.9 \%$ of all participants had serum TSH levels within the reference range, while $9.2 \%$ had decreased TSH levels and 2.9\% had increased TSH levels. The serum TSH levels in men were significantly lower than in women (table 1). The volume of VAT in men was twice as high as in women, whereas women had a significantly higher volume of SAT. Women tended to have higher cholesterol levels and HDL cholesterol levels, whereas men had higher triglyceride levels. In both sexes, BMI, waist circumference, and waist-to-height ratio were all significantly higher in men than in women. 


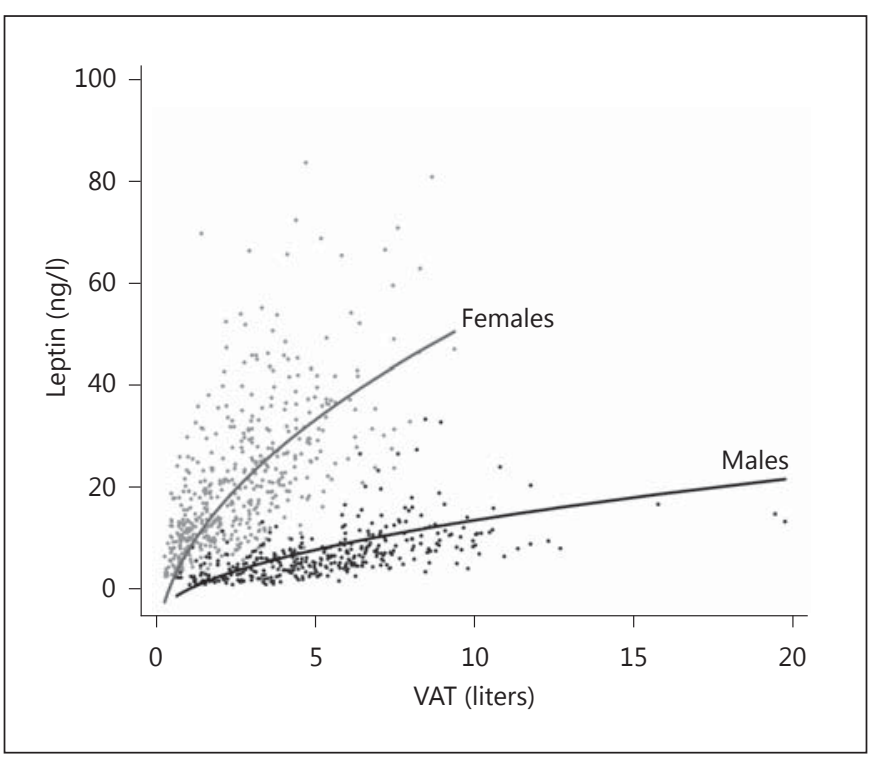

Fig. 1. Association between VAT and leptin. VAT was measured by interpretation of whole body MRIs, and serum leptin levels were determined in blood samples.

We found that the association between TSH and VAT was not effect-modified by sex, but by smoking $(\mathrm{p}<0.001$ for effect modification through smoking). There was no association observed between TSH and VAT, and there were no associations between low or high TSH and VAT. We reported $\beta$-coefficients because we only found linear associations between TSH and VAT (table 2). In the unadjusted analysis between TSH and VAT, we observed a significant inverse relationship ( $\mathrm{p}<0.001$ ), which became nonsignificant after adjusting for covariates. Second, we observed a significant inverse association of a normal TSH with VAT $(\mathrm{p}=0.004)$ in the adjusted multivariable analysis, but neither low nor high TSH were significantly associated with VAT.

We compared our primary outcome of VAT with other anthropometric measures of adiposity in fully adjusted regression models (table 3 ) and demonstrated an initially significant association between TSH and waist-to-height ratio $(\mathrm{p}=0.046)$. No association was observed between TSH and SAT, BMI, waist circumference, hip circumference, or waist-to-height ratio. We explored the role of leptin in 2 multivariable analyses in 366 men and 485 women. The association of leptin and VAT was exponential and stronger for women than for men (both $\mathrm{p}<0.001$, fig. 1). The analysis of the association between TSH and leptin yielded also a weaker but highly significant ( $\mathrm{p}<$ 0.001 ) relationship (fig. 2).

Association between TSH and Visceral Body Fat

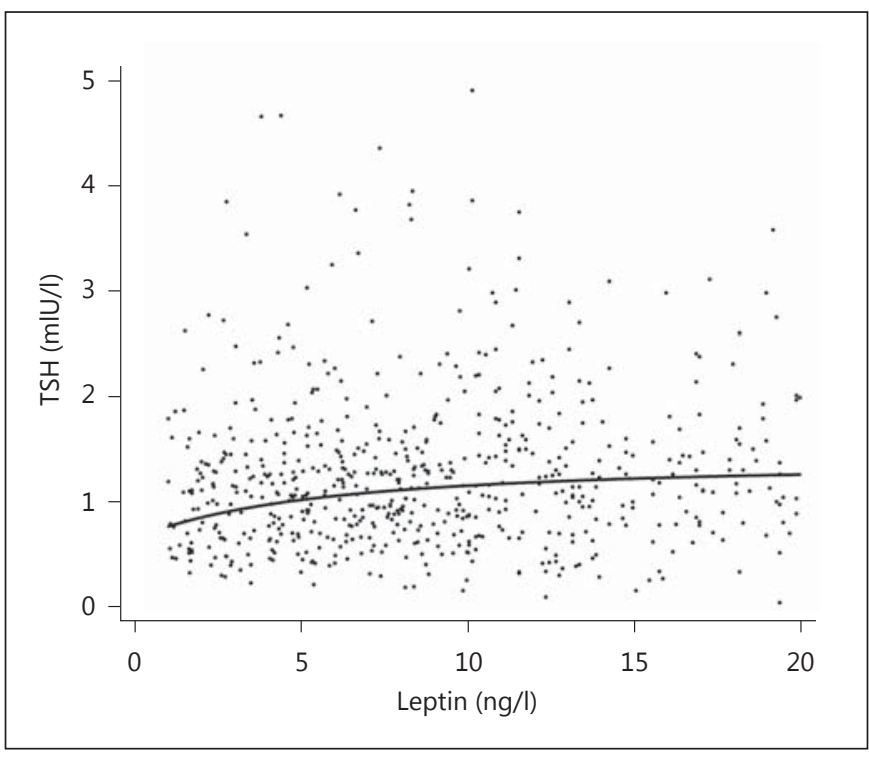

Fig. 2. Association between leptin and TSH. Serum leptin levels and TSH were determined in blood samples.

A subgroup analysis by smoking status raised the possibility of a positive association ( $\mathrm{p}=0.005)$ among former smokers (table 4). As a further exploratory analysis, we divided the normally distributed age into quartiles, and stratified by sex and BMI (data not shown), but did not detect any association between TSH and VAT. Applying the Bonferroni correction on the results made the associations of TSH and waist-to-height ratio as well as the result for former smokers insignificant.

\section{Discussion}

We found no association between serum TSH and the volume of VAT. However, leptin could be a possible link as it is associated with both VAT and TSH.

As the first population-based study using MRI techniques to ascertain body fat and its relation with thyroid function, the present study's results align well with findings of a Greek prevention study of healthy individuals that failed to show an association between TSH levels and visceral fat thickness [22]. Likewise, a Belgian study demonstrated that there were no associations between TSH and the whole body fat mass, and a South Korean study in men found no association between TSH and visceral and subcutaneous fat area [23,25]. Our study differed in that the volume of VAT in the aforementioned studies 
Table 2. Association between TSH and VAT for the overall population

\begin{tabular}{|c|c|c|c|c|c|}
\hline & \multirow{2}{*}{$\begin{array}{l}\text { Subjects, } \\
\mathrm{n}\end{array}$} & \multicolumn{2}{|l|}{ Crude } & \multicolumn{2}{|l|}{ Adjusted } \\
\hline & & $\beta$-coefficient & $95 \% \mathrm{CI}$ & $\beta$-coefficient & $95 \% \mathrm{CI}$ \\
\hline TSH & 1,955 & -0.30 & $-0.43,-0.17$ & 0.06 & $-0.02,0.14$ \\
\hline Low TSH & 179 & -0.52 & $-3.94,2.92$ & -1.72 & $-4.86,1.42$ \\
\hline High TSH & 57 & -0.12 & $-0.35,0.11$ & 0.10 & $-0.04,0.24$ \\
\hline TSH within reference range & 1,719 & -0.42 & $-0.66,-0.19$ & -0.41 & $-0.69,-0.13$ \\
\hline
\end{tabular}

Low TSH $=<0.49 \mathrm{mIU} / \mathrm{l}$; high TSH = >3.29 mIU/l; TSH within reference range $=0.49-3.29 \mathrm{mIU} / \mathrm{l}$. Adjusted model includes age, sex, smoking, physical activity, and alcohol intake as covariates.

Table 3. Association between TSH and anthropometric markers

\begin{tabular}{llll}
\hline & $\beta$-coefficient & $95 \%$ CI & $\begin{array}{l}\text { Standardized } \\
\beta \text {-coefficient }\end{array}$ \\
\hline VAT (MRI) (liters) & 0.06 & $-0.02,0.14$ & 1.44 \\
SAT (MRI) (liters) & 0.10 & $-0.06,0.26$ & 1.22 \\
BMI & 0.16 & $-0.05,0.36$ & 1.49 \\
Waist circumference (cm) & 0.43 & $-0.03,0.90$ & 1.84 \\
Hip circumference (cm) & 0.16 & $-0.22,0.54$ & 0.84 \\
Waist-to-hip ratio & 0.01 & $0.00005,0.005$ & 2.00 \\
Waist-to-height ratio & 0.01 & $-0.0007,0.006$ & 1.50 \\
\hline
\end{tabular}

Adjusted model includes age, sex, smoking, physical activity, and alcohol intake as covariates. Standardized $\beta$-coefficient $=\beta$-coefficient $/$ standard error.

Table 4. Association between TSH and VAT stratified by smoking status

\begin{tabular}{|c|c|c|c|c|c|}
\hline & \multirow{2}{*}{$\begin{array}{l}\text { Subjects, } \\
\mathrm{n}\end{array}$} & \multicolumn{2}{|l|}{ Crude } & \multicolumn{2}{|l|}{ Adjusted } \\
\hline & & $\beta$-coefficient & $95 \% \mathrm{CI}$ & $\beta$-coefficient & $95 \% \mathrm{CI}$ \\
\hline Never smokers & 771 & -0.30 & $-0.51,-0.08$ & -0.02 & $-0.12,0.08$ \\
\hline Former smokers & 716 & -0.23 & $-0.43,-0.03$ & 0.18 & $0.06,0.31$ \\
\hline Current smokers & 468 & -0.40 & $-0.63,-0.17$ & -0.01 & $-0.23,0.22$ \\
\hline
\end{tabular}

Adjusted model includes age, sex, smoking, physical activity, and BMI as covariates.

was measured using computer tomography or indirectly via the measurement of preperitoneal fat with ultrasound. An Italian study in patients with obesity used computer tomography scans to determine VAT and showed a significant association of TSH and VAT [24]. Their sample size was fairly small and the characteristics of an obese population certainly differ from our general population sample [33].
Comparable population-based studies have not specifically assessed VAT or SAT, but used anthropometric markers. Focusing our secondary analysis on these relationships, we did not observe similar results. We were unable to replicate the association between TSH and BMI in women from a previous, independent SHIP examination performed in the same study region [14], despite adjusting for the same confounders and stratifying by sex.
16
Eur Thyroid J 2017;6:12-19 DOI: $10.1159 / 000450977$
Witte/Völzke/Lerch/Hegenscheid/ Friedrich/Ittermann/Batsis 
The association was weak and, compared to this study, there was a different baseline response which could have resulted in a different selection bias. More importantly, in the 10 years between the previous SHIP examination and our study, many characteristics had changed, for example, an increased iodine supply [4]. Results of other population-based studies have been mixed. Recent longitudinal data suggested an association between the change of TSH and the change of body fat; however, no association has been observed in baseline TSH and change in body fat or in change in TSH and baseline body fat measurements $[19,20]$. Despite the prospective design of these studies, a causal link could not be proven beyond doubt [20]. A large Norwegian study found a positive association between TSH and BMI in a cross-sectional approach, [34], whereas an Australian and Dutch study did not $[15,16]$. The Norwegian sample was large $(n=27,097)$; however, only subjects older than 40 years were included in the study, which could have affected the representativeness of the study [34]. It has been shown that anthropometric measures change with age [35], which is also true for serum TSH levels [36]. More importantly, these studies relied solely on anthropometric surrogates for the relationship of TSH and fat, yet BMI can be a fairly inaccurate measure for adiposity, particularly in men and in the elderly [37].

Our results may indicate that the volume of VAT may not necessarily correspond to the density of TSH receptors and thyroid hormone receptor $\alpha_{1}$, which are expressed on preadipocytes and adipocytes and which are important regulators of adipocyte differentiation [38]. The exact role of the receptors of TSH receptors and thyroid hormone receptor $\alpha_{1}$ within the described relationship between thyroid function and VAT remains incompletely understood. One study of 119 subjects found a significantly reduced number of TSH receptors in adipose tissue in people with obesity [39], while another showed an increased TSH receptor expression in obese mice and humans [38]. Although purely speculative, TSH receptors may be distributed unevenly throughout the VAT, suggesting that the effects of $\mathrm{fT}_{3}$ or $\mathrm{fT}_{4}$ on total weight loss do not correlate with the hormone dose [40]. Other possibilities to explain the lack of a direct association between TSH and VAT include impaired water homeostasis in persons with low thyroid function [41] or the existence of a latency period between the onset of TSH decrease and the increase of the visceral fat volume [18]. According to these speculations, a certain proportion of participants with low TSH levels may only develop an increase in visceral fat in the future.

Association between TSH and Visceral Body Fat
Although we did not prove a direct association between VAT and TSH, we propose that leptin may be a possible link in this pathway as it is strongly associated with both VAT and TSH in the VAT-leptin-TSH pathway [25]. VAT produces a number of adipokines, including leptin [42], which may influence and regulate the secretory capacity of the thyroid gland as well as the production of thyrotropin-releasing hormone in the pituitary gland $[10,11]$. While the VAT-leptin association has been well studied and the association of SAT with leptin is even stronger [43], we concur that further studies are needed not only to prove the leptin-TSH association, but also to show that leptin is secreted from nonadipose tissues [44-46]. Two possibilities may explain our findings of no direct but indirect association of VAT and TSH via leptin if we consider a causal pathway between VAT and TSH: (1) the percentage of VAT compared to other adipose tissue is highly variable in a population which would confound the relationship, and (2) the adipokine production within adipose tissue is disproportional and uneven [47]. Indicative for this hypothesis is that studies have shown that there is at least regional variation in the expression of the leptin gene expression [48]. We considered the inverse association between TSH within the reference range and VAT as a chance finding, given that there are no physiological explanatory models that could support this association and the nonsignificance after accounting for multiple analyses.

To our knowledge, this study is the first to examine the association of TSH and VAT in a large study sample. Unlike previous studies, we included both women and men in our study and chose a population-based approach with a geographically circumscribed sample, a strength in this epidemiology study that allows extrapolation to other regions with similar demographic characteristics [23-25]. Such a study design minimizes the referral and selection bias observed in studies conducted in tertiary care centers [49]. MRI ascertainment of body fat avoided the need to utilize anthropometric measures which are known to be susceptible to measurement bias [50]. Our relatively high participant number allowed us to assess subtle associations.

We recognize that this study has a number of limitations. The cross-sectional design does not allow us to determine causality and we caution the reader that our results imply associations only. Longitudinal data will be available with the follow-up study of SHIP-Trend after 2017 and could certainly confirm our results, although it is possible that our sample size is still too small for a potential weak association. A considerable nonresponse rate (49\%) was observed which may risk biasing the analyses. This number has to be accounted for within the context 
of declining participation in large-scale population-based studies affecting other major cohort studies [51]. Further methodological research should examine the extent of the representativeness of this research. It remains possible that a positive association may have been overlooked in specific subgroups due to insufficient statistical power. We also acknowledge the lack of data on other thyroid hormones including $\mathrm{fT}_{3}, \mathrm{fT}_{4}$, thyroid peroxidase, and thyroid receptor antibodies, including plasma levels of free fatty acids and interleukin 6 . However, we believe that TSH as the most sensitive marker of thyroid function is the appropriate parameter to measure this association. There is some inconsistency in the anatomical boundaries of the abdomen, which could alter the measurement of VAT [52], but they are naturally still more accurate than the anthropometric measures which can only serve as crude indicators of adiposity. Finally, we applied a very conservative approach to test significance using the Bonferroni correction and recognize that this compromised the significance of our results.

To conclude, we could not demonstrate a direct association between TSH and VAT in the surveyed population in West Pomerania. Longitudinal population-based studies with larger sample sizes and research in other regions have to be conducted to confirm the results of this study.

\section{Acknowledgement}

The authors would like to thank Jeremiah R. Brown for his assistance in the early editing of the manuscript. The Study of Health in Pomerania is part of the Community Medicine Research Network of the University Medicine Greifswald, which was funded by the German Federal Ministry for Education and Research, the Federal Ministry of Food and Agriculture, the Ministry for Education, Research and Cultural Affairs of the State Mecklenburg-Western Pomerania, and the Ministry for Social Affairs of the State Mecklenburg-Western Pomerania. Analyses were further supported by the German Research Foundation (DFG VO955/12-1). Support was provided in part by the Dartmouth Health Promotion and Disease Prevention Research Center supported by Cooperative Agreement No. U48DP005018 from the Centers for Disease Control and Prevention. The findings and conclusions in this journal article are those of the authors and do not necessarily represent the official position of the Centers for Disease Control and Prevention. The study was partially funded by the Department of Medicine and the Dartmouth Centers for Health and Aging.

\section{Disclosure Statement}

The authors declare that there is no conflict of interest that could be perceived as prejudicing the impartiality of the research.

\section{References}

1 Vanderpump MP, Tunbridge WM, French JM, Appleton D, Bates D, Clark F, Grimley Evans J, Hasan DM, Rodgers H, Tunbridge F, et al: The incidence of thyroid disorders in the community: a twenty-year follow-up of the Whickham Survey. Clin Endocrinol (Oxf) 1995;43:55-68.

2 Volzke H, Ludemann J, Robinson DM, Spieker KW, Schwahn C, Kramer A, John U, Meng W: The prevalence of undiagnosed thyroid disorders in a previously iodine-deficient area. Thyroid 2003;13:803-810.

$3 \mathrm{Ng} \mathrm{M}$, Fleming T, Robinson M, Thomson B, Graetz N, Margono C: Global, regional, and national prevalence of overweight and obesity in children and adults during 1980-2013: a systematic analysis for the global burden of disease study 2013. Lancet 2014;384:766-781.

4 Volzke H, Ittermann T, Schmidt CO, Baumeister SE, Schipf S, Alte D, Biffar R, John U, Hoffmann W: Prevalence trends in lifestylerelated risk factors. Dtsch Arztebl Int 2015; 112:185-192.
5 Mensink GB, Schienkiewitz A, Haftenberger M, Lampert T, Ziese T, Scheidt-Nave C: Overweight and obesity in Germany: results of the German Health Interview and Examination Survey for Adults (DEGS1) (in German). Bundesgesundheitsblatt Gesundheitsforschung Gesundheitsschutz 2013;56:786-794.

6 Lu S, Guan Q, Liu Y, Wang H, Xu W, Li X, Fu Y, Gao L, Zhao J, Wang X: Role of extrathyroidal TSHR expression in adipocyte differentiation and its association with obesity. Lipids Health Dis 2012;11:17.

7 Nannipieri M, Cecchetti F, Anselmino M, Camastra S, Niccolini P, Lamacchia M, Rossi M, Iervasi G, Ferrannini E: Expression of thyrotropin and thyroid hormone receptors in adipose tissue of patients with morbid obesity and/or type 2 diabetes: Effects of weight loss. Int J Obes (Lond) 2009;33:1001-1006; erratum Int J Obes (Lond) 2010;34:215.

8 Nomura E, Toyoda N, Harada A, Nishimura K, Ukita C, Morimoto S, Kosaki A, Iwasaka T, Nishikawa M: Type 2 iodothyronine deiodinase is expressed in human preadipocytes. Thyroid 2011;21:305-310.

9 Farooqi IS, O’Rahilly S: 20 years of leptin: $\mathrm{Hu}$ man disorders of leptin action. J Endocrinol 2014;223:T63-T70.
10 Nillni EA, Vaslet C, Harris M, Hollenberg A, Bjorbak C, Flier JS: Leptin regulates prothyrotropin-releasing hormone biosynthesis. Evidence for direct and indirect pathways. J Biol Chem 2000;275:36124-36133.

11 Legradi G, Emerson CH, Ahima RS, Rand WM, Flier JS, Lechan RM: Arcuate nucleus ablation prevents fasting-induced suppression of ProTRH mRNA in the hypothalamic paraventricular nucleus. Neuroendocrinology 1998;68:89-97.

12 Betry C, Challan-Belval MA, Bernard A, Charrie A, Drai J, Laville M, Thivolet C, Disse E: Increased TSH in obesity: evidence for a BMI-independent association with leptin. Diabetes Metab 2015;41:248-251.

13 Lucas A, Granada ML, Olaizola I, Castell C, Julian MT, Pellitero S, Roca J, Puig-Domingo $\mathrm{M}$ : Leptin and thyrotropin relationship is modulated by smoking status in euthyroid subjects. Thyroid 2013;23:964-970.

14 Friedrich N, Rosskopf D, Brabant G, Volzke $\mathrm{H}$, Nauck M, Wallaschofski H: Associations of anthropometric parameters with serum TSH, prolactin, IGF-I, and testosterone levels: results of the Study of Health in Pomerania (SHIP). Exp Clin Endocrinol Diabetes 2010; 118:266-273. 
15 Makepeace AE, Bremner AP, O'Leary P, Leedman PJ, Feddema P, Michelangeli V, Walsh JP: Significant inverse relationship between serum free $\mathrm{T}_{4}$ concentration and body mass index in euthyroid subjects: differences between smokers and nonsmokers. Clin Endocrinol (Oxf) 2008;69:648-652.

16 Manji N, Boelaert K, Sheppard MC, Holder RL, Gough SC, Franklyn JA: Lack of association between serum TSH or free $\mathrm{T}_{4}$ and body mass index in euthyroid subjects. Clin Endocrinol (Oxf) 2006;64:125-128.

17 Sakurai M, Nakamura K, Miura K, Yoshita K, Takamura T, Nagasawa SY, Morikawa Y, Ishizaki M, Kido T, Naruse Y, Nakashima M, Nogawa K, Suwazono Y, Nakagawa H: Association between a serum thyroid-stimulating hormone concentration within the normal range and indices of obesity in Japanese men and women. Intern Med 2014;53:669-674.

18 Bjergved L, Jorgensen T, Perrild H, Laurberg P, Krejbjerg A, Ovesen L, Rasmussen LB, Knudsen N: Thyroid function and body weight: a community-based longitudinal study. PLoS One 2014;9:e93515.

19 Fox CS, Pencina MJ, D'Agostino RB, Murabito JM, Seely EW, Pearce EN, Vasan RS: Relations of thyroid function to body weight: cross-sectional and longitudinal observations in a community-based sample. Arch Intern Med 2008;168:587-592.

20 Svare A, Nilsen TI, Bjoro T, Asvold BO, Langhammer A: Serum TSH related to measures of body mass: longitudinal data from the HUNT Study, Norway. Clin Endocrinol (Oxf) 2011; 74:769-775.

21 Wesche MF, Wiersinga WM, Smits NJ: Lean body mass as a determinant of thyroid size. Clin Endocrinol (Oxf) 1998;48:701-706.

22 Alevizaki M, Saltiki K, Voidonikola P, Mantzou E, Papamichael C, Stamatelopoulos K: Free thyroxine is an independent predictor of subcutaneous fat in euthyroid individuals. Eur J Endocrinol 2009;161:459-465.

23 Moon MK, Hong ES, Lim JA, Cho SW, Soo L, Choi SH, Yi KH, Park do J, Park YJ, Jang HC: Associations between thyroid hormone levels and regional fat accumulation in euthyroid men. Eur J Endocrinol 2013;168:805-810.

24 Muscogiuri G, Sorice GP, Mezza T, Prioletta A, Lassandro AP, Pirronti T, Della Casa S, Pontecorvi A, Giaccari A: High-normal TSH values in obesity: is it insulin resistance or adipose tissue's guilt? Obesity 2013;21:101-106.

25 Roef G, Lapauw B, Goemaere S, Zmierczak HG, Toye K, Kaufman JM, Taes Y: Body composition and metabolic parameters are associated with variation in thyroid hormone levels among euthyroid young men. Eur J Endocrinol 2012;167:719-726.

26 Baumeister SE, Alte D, Meyer C, John U: Health risk drinking and problematic consumption of alcohol in Pomerania: comparative analysis of the Study of Health in Pomerania (SHIP) compared with the Federal German
Health and Examination Survey in 1998 (in German). Gesundheitswesen 2005;67:39-47.

27 Kawachi I, Kennedy BP: The relationship of income inequality to mortality: does the choice of indicator matter? Soc Sci Med 1997; 45:1121-1127.

28 Ittermann T, Khattak RM, Nauck M, Cordova CM, Volzke H: Shift of the TSH reference range with improved iodine supply in Northeast Germany. Eur J Endocrinol 2015;172: 261-267.

29 Hegenscheid K, Kuhn JP, Volzke H, Biffar R, Hosten N, Puls R: Whole-body magnetic resonance imaging of healthy volunteers: pilot study results from the population-based SHIP study. Rofo 2009;181:748-759.

30 Müller HP, Raudies F, Unrath A, Neumann $\mathrm{H}$, Ludolph AC, Kassubek J: Quantification of human body fat tissue percentage by MRI. NMR Biomed 2011;24:17-24.

31 Royston P, Sauerbrei W: Multivariable Model-Building a Pragmatic Approach to Regression Analysis Based on Fractional Polynomials for Continuous Variables; Wiley Series in Probability and Statistics. Chichester, Wiley, 2008, vol XVII, p 303.

32 Bonferroni CE: Teoria statistica delle classi e calcolo delle probabilità. Pub R Ist Sup Sci Econ Com Fir 1936;8:3-62.

33 Fujioka S, Matsuzawa Y, Tokunaga K, Tarui S: Contribution of intra-abdominal fat accumulation to the impairment of glucose and lipid metabolism in human obesity. Metabolism 1987;36:54-59.

34 Asvold BO, Bjoro T, Vatten LJ: Association of serum TSH with high body mass differs between smokers and never-smokers. J Clin Endocrinol Metab 2009;94:5023-5027.

35 Perissinotto E, Pisent C, Sergi G, Grigoletto F: Anthropometric measurements in the elderly: age and gender differences. Br J Nutr 2002; 87:177-186.

36 Bremner AP, Feddema P, Leedman PJ, Brown SJ, Beilby JP, Lim EM, Wilson SG, O'Leary PC, Walsh JP: Age-related changes in thyroid function: a longitudinal study of a community-based cohort. J Clin Endocrinol Metab 2012;97:1554-1562.

37 Romero-Corral A, Somers VK, Sierra-Johnson J, Thomas RJ, Collazo-Clavell ML, Korinek J, Allison TG, Batsis JA, Sert-Kuniyoshi FH, Lopez-Jimenez F: Accuracy of body mass index in diagnosing obesity in the adult general population. Int J Obes (Lond) 2008;32: 959-966.

$38 \mathrm{Lu} \mathrm{S}$, Guan Q, Liu Y, Wang H, Xu W, Li X, Fu Y, Gao L, Zhao J, Wang X: Role of extrathyroidal TSHR expression in adipocyte differentiation and its association with obesity. Lipids Health Dis 2012;11:17.

39 Nannipieri M, Cecchetti F, Anselmino M, Camastra S, Niccolini P, Lamacchia M, Rossi M, Iervasi G, Ferrannini E: Expression of thyrotropin and thyroid hormone receptors in adipose tissue of patients with morbid obesity and/or type 2 diabetes: effects of weight loss. Int J Obes (Lond) 2009;33:10011006.

40 Kaptein EM, Beale E, Chan LS: Thyroid hormone therapy for obesity and nonthyroidal illnesses: a systematic review. J Clin Endocrinol Metab 2009;94:3663-3675.

41 Santini F, Pinchera A, Marsili A, Ceccarini G Castagna MG, Valeriano R, Giannetti $M$, Taddei D, Centoni R, Scartabelli G, Rago T, Mammoli C, Elisei R, Vitti P: Lean body mass is a major determinant of levothyroxine dosage in the treatment of thyroid diseases. J Clin Endocrinol Metab 2005;90:124-127.

42 Klein S, Coppack SW, Mohamed-Ali V, Landt M: Adipose tissue leptin production and plasma leptin kinetics in humans. Diabetes 1996; 45:984-987.

43 Ruhl CE, Everhart JE, Ding J, Goodpaster BH, Kanaya AM, Simonsick EM, Tylavsky FA, Harris TB: Serum leptin concentrations and body adipose measures in older black and white adults. Am J Clin Nutr 2004;80:576-583.

44 Bado A, Levasseur S, Attoub S, Kermorgant S, Laigneau JP, Bortoluzzi MN, Moizo L, Lehy T, Guerre-Millo M, Le Marchand-Brustel Y, Lewin MJ: The stomach is a source of leptin. Nature 1998;394:790-793.

45 Masuzaki H, Ogawa Y, Sagawa N, Hosoda K Matsumoto T, Mise H, Nishimura H, Yoshimasa Y, Tanaka I, Mori T, Nakao K: Nonadipose tissue production of leptin: leptin as a novel placenta-derived hormone in humans. Nat Med 1997;3:1029-1033.

46 Morash B, Li A, Murphy PR, Wilkinson M, Ur $\mathrm{E}$ : Leptin gene expression in the brain and pituitary gland. Endocrinology 1999;140:59955998.

47 Masuzaki H, Ogawa Y, Isse N, Satoh N, Okazaki T, Shigemoto M, Mori K, Tamura N, Hosoda K, Yoshimasa Y, et al: Human obese gene expression. Adipocyte-specific expression and regional differences in the adipose tissue. Diabetes 1995;44:855-858.

48 Montague CT, Prins JB, Sanders L, Digby JE, O'Rahilly S: Depot- and sex-specific differences in human leptin mRNA expression: implications for the control of regional fat distribution. Diabetes 1997;46:342-347.

49 Sackett DL: Bias in analytic research. J Chronic Dis 1979;32:51-63.

50 Panoulas VF, Ahmad N, Fazal AA, Kassamali RH, Nightingale P, Kitas GD, Labib M: The inter-operator variability in measuring waist circumference and its potential impact on the diagnosis of the metabolic syndrome. Postgrad Med J 2008;84:344-347.

51 Watts G: UK biobank gets 10\% response rate as it starts recruiting volunteers. BMJ 2007; 334:659.

52 Shen W, Wang Z, Punyanita M, Lei J, Sinav A, Kral JG, Imielinska C, Ross R, Heymsfield SB: Adipose tissue quantification by imaging methods: a proposed classification. Obes Res 2003;11:5-16. 